\title{
Profile of subgrade subsidence in Sorchen
}

\author{
Nimesh Chettri ${ }^{1}$, Indra Bdr.Chhetri ${ }^{2}$, Karma Yangzom $^{3}$ \\ ${ }^{1}$ Associate lecturer, Department of Civil engineering, College of Science and Technology, \\ Phuentsholing (21101) Bhutan \\ ${ }^{2}$ Associate lecturer, Department of Survey engineering, Jigme Namgyal Engineering College. \\ Deothang (41000) Bhutan \\ ${ }^{3}$ Assistant lecturer, Department of Civil engineering, College of Science and Technology \\ Phuentsholing (21101) Bhutan
}

Email:nimeshchhetri.cst@rub.edu.bt, indrachhetri@jnec.edu.bt, karmayangzom.cst@rub.edu.bt

\begin{abstract}
The highway along Sorchen have been imperiled to various mechanical damages posing tremendous problems to the road users. These damages of road and its sub-grade are contributed by number of factors both manmade and natural. This research focuses on identification of damaged subgrade and its causes to the measurable degree. The greater emphasis has been turned to the Geotechnical site investigation of the affected areas and quantification of the results for the benefit of the policy makers in future. The survey has been carried out to ensure the extend of subsidence of the road and shown in the graphical manner. Wenner's 4 Spikes method ground resistivity test were also carried out to explore the sub surface of the affected subgrade. The research has also done on the possibilities of rigid slab supported by the pile foundation as the counter measures. The results obtained by the electrical resistivity test will be used to located the depth of pile foundation.
\end{abstract}

Keywords: Road sinking, Geophysical Site Characterization, Geophysical Investigation, identification, Engineering solution, Thromdae.

\section{INTRODUCTION}

Bhutan covers an area of 38,000 square kilometers in the Eastern part of the Himalayas ranging between $26^{\circ} 40^{\prime}$ and $28^{\circ} 20^{\prime}$ North and longitude $88^{\circ} 45^{\prime}$ and $92^{\circ} 7^{\prime}$ 'East. Bhutan is also a developing country for Bhutan had initiated and accelerated its development works since the early nineties. The developmental works in the country till date had been made possible with smooth and effective transportation and exchange of goods with single nearest trade partner, India along the Thimphu-Phuentsholing highway. However, this particular highway is the riskiest route with increased road blockages along the highway during the monsoon season eventually endangering the country's economy (Road Safety and Transport Authority, 1991-2002).

\subsection{Study Area}

Sorchen lies within the stretch of Thimphu-Phuentsholing highway with a fragile terrain and is geologically an unstable region. The study area lies in the active seismic zone leading to numerous geological problems like landslide and highway sinking. Sorchen has posed problems to Bhutanese people since the first landslide in the area occurred in 1983 (The Bhutan society newsletter, July 2002).

Its elevation ranges from 230 meters to 2055 meters approximately from mean sea level. It starts from 0+00 Km (Phuentsholing) and ends at $21+00 \mathrm{Km}$ (Sorchen) along the stretch from ThimphuPhuentsholing Highway. Being unstable and unsuitable for agriculture, this area is sparsely populated. The detail survey along the Thimphu Phuentsholing highway was carried out and four critical areas were located along with the amount of subsidence the subgrade has undergone to. 


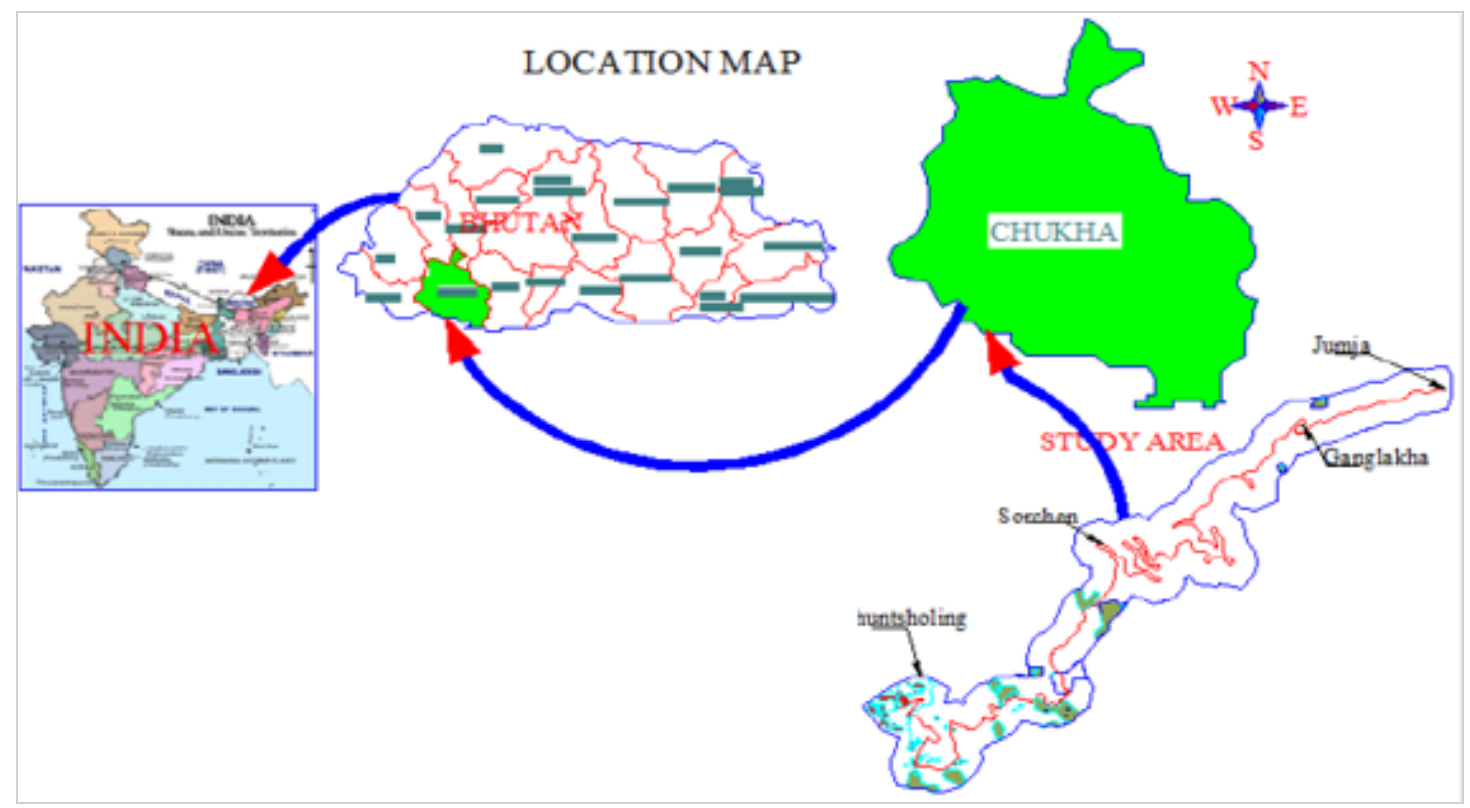

Fig 1: Location of study area (Source: International Journal of Advanced Scientific Research and Technology, volume 3, July 2012)

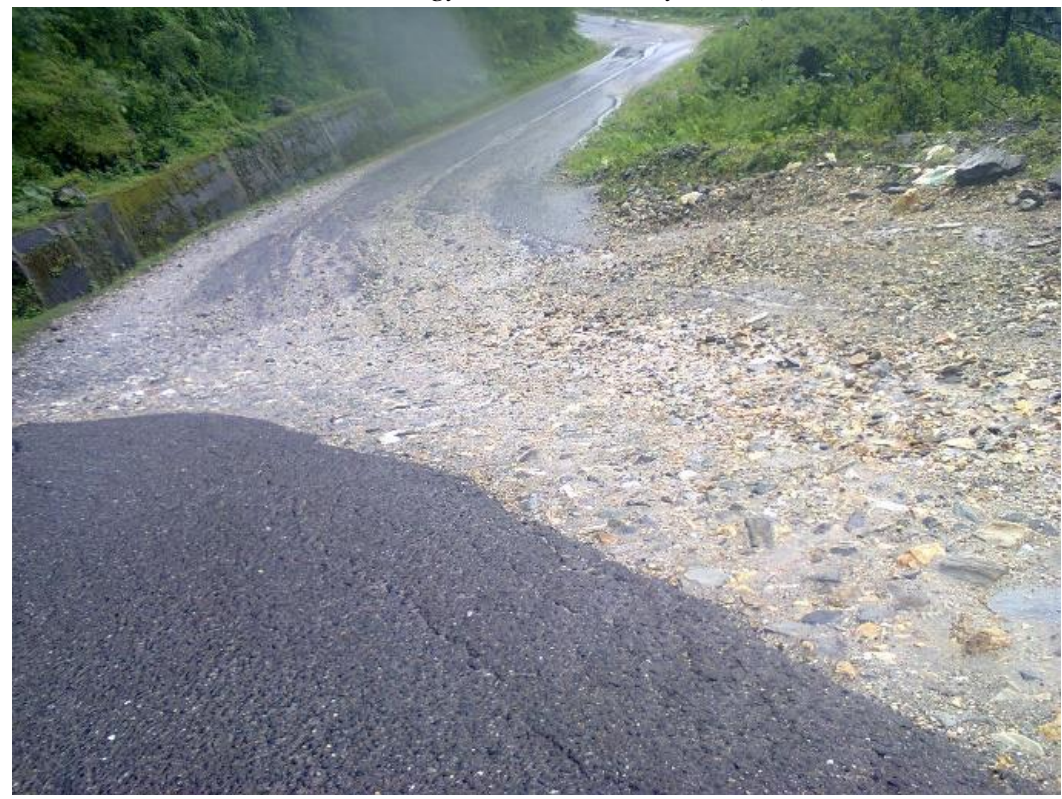

Fig 2: Road Section in Sorchen (Zone-4) showing the subsidence profile

\begin{tabular}{|c|c|c|c|c|}
\hline Sl.No. & Zone & Coordinates & Elevation(m) & $\begin{array}{c}\text { Maximum } \\
\text { Subsidence(m) }\end{array}$ \\
\hline 1 & Zone I & $\begin{array}{c}\mathrm{N} 26.891763^{\circ} \\
\mathrm{E} 89.443123^{\circ}\end{array}$ & 1389 & 0.54 \\
\hline 2 & Zone II & $\begin{array}{l}\mathrm{N} 26.888123^{\circ} \\
\mathrm{E} 89.436397^{\circ}\end{array}$ & 1142 & 0.81 \\
\hline 3 & Zone III & $\mathrm{N} 26.885973^{\circ}$ & 1019 & 0.79 \\
& & $\mathrm{E} \mathrm{89.436996^{ \circ }}$ & & 0.74 \\
\hline 4 & Zone IV & $\mathrm{N} 26.868926^{\circ}$ & 765 & \\
\hline
\end{tabular}

Table 1: Study area Zonation and its subsidence depth 


\section{METHODOLOGY}

\subsection{Preliminary Survey}

A detailed topographical survey was conducted and result is presented in table 1 . The preliminary survey for the assessment of subsidence area along the Phuentsholing-Thimphu highway at Sorchen have shown four critical pavement subsidence zones. The profile of these critical zones is shown in figure 4, 5, 6 and 7. These zones are seen to be temporarily maintained through normal practice of re-surfacing; however, the problem of sinking remains unsolved for the past last decades(K. Tempa, N. Chhetri, I Bdr, 2016). The zones were identified as Zone I, II, III and IV.

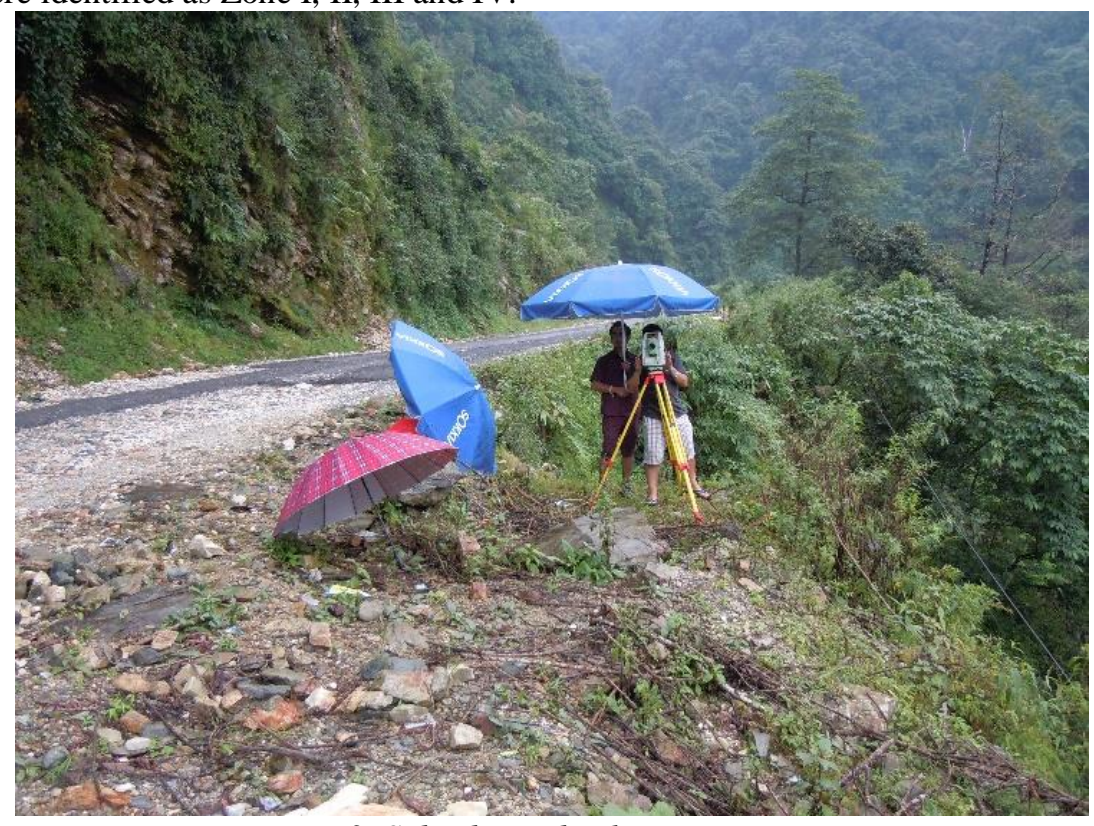

Fig 3: Subsidence depth measurement

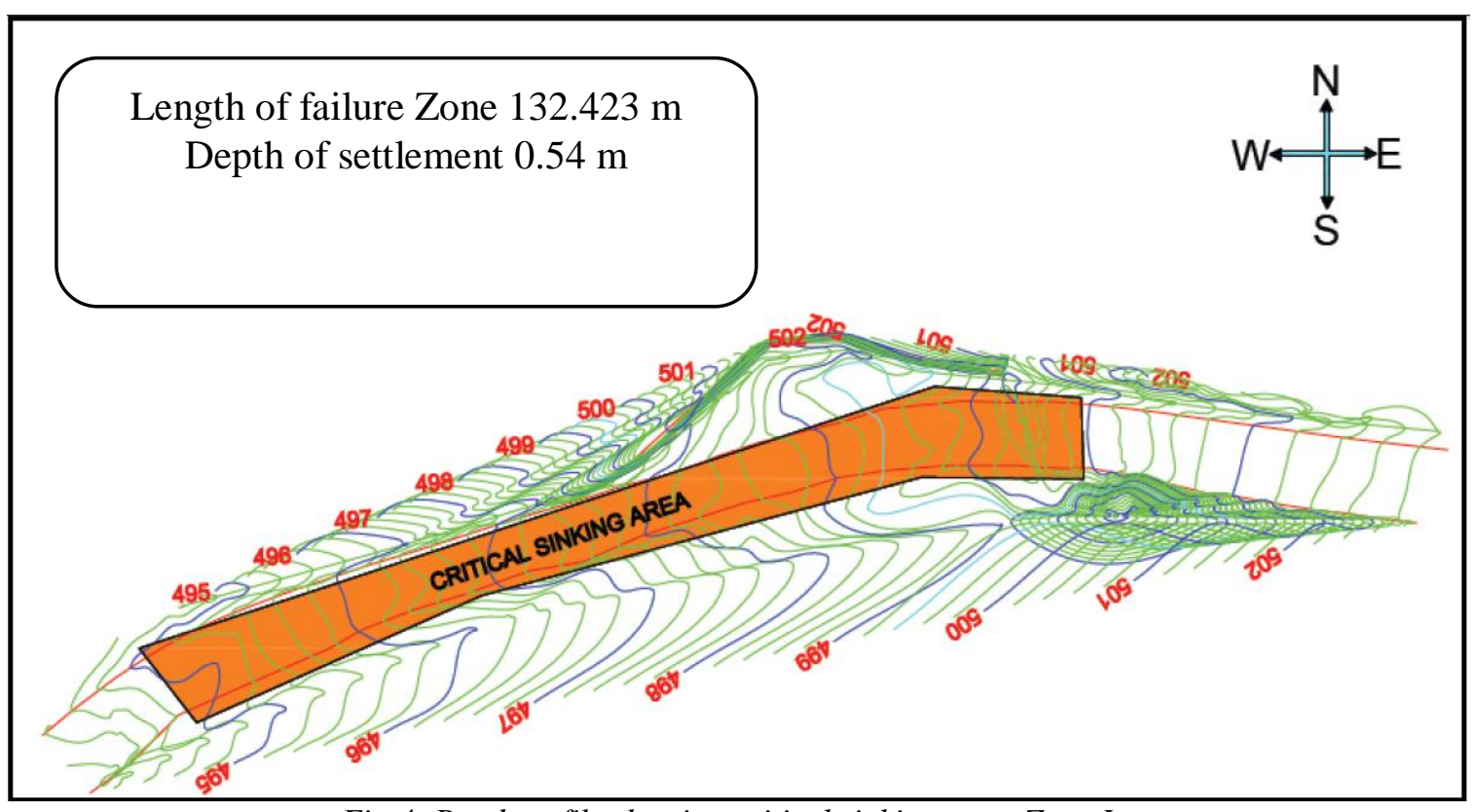

Fig 4: Road profile showing critical sinking area, Zone I 


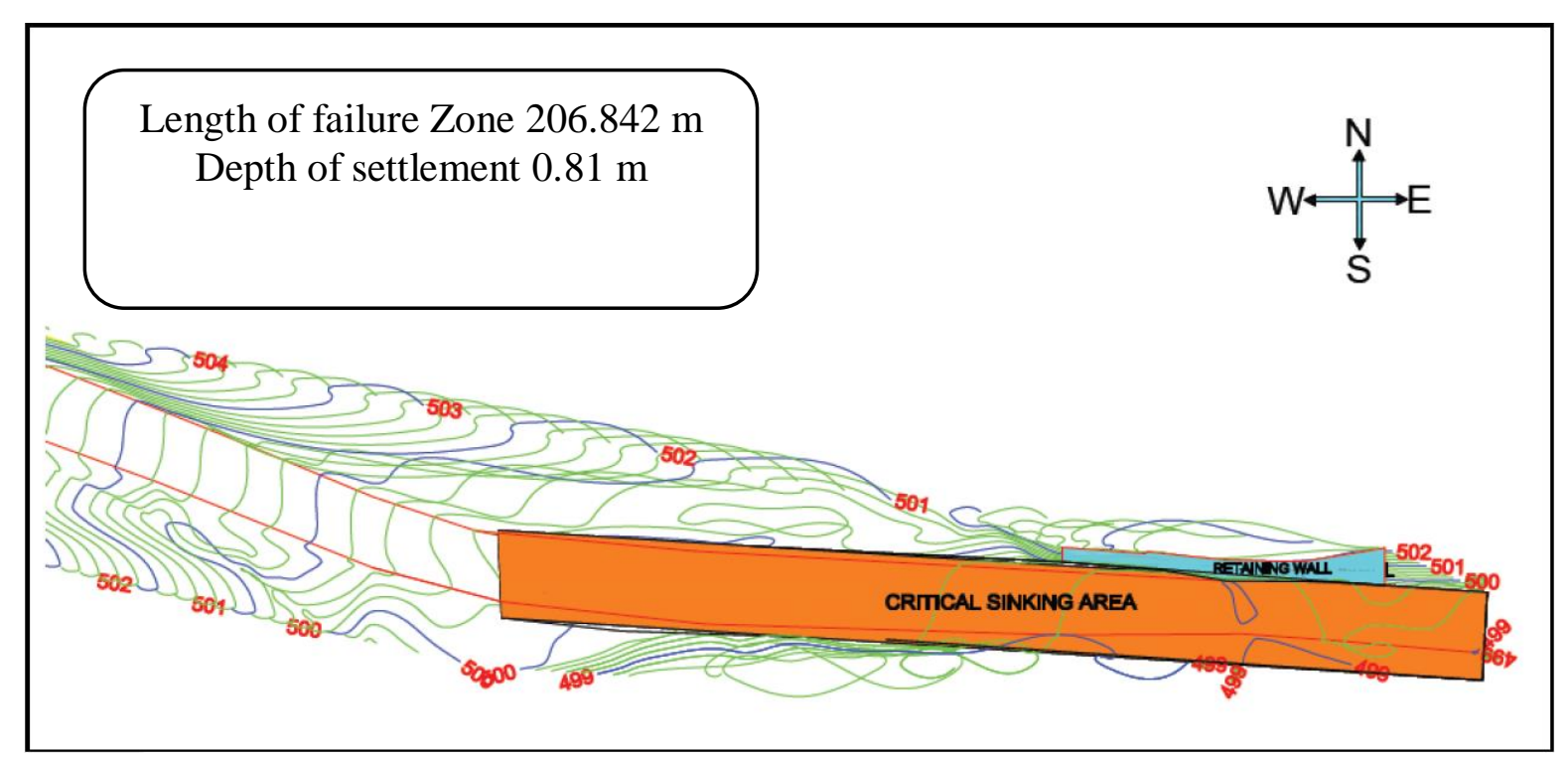

Fig 5: Road profile showing critical sinking area, Zone II

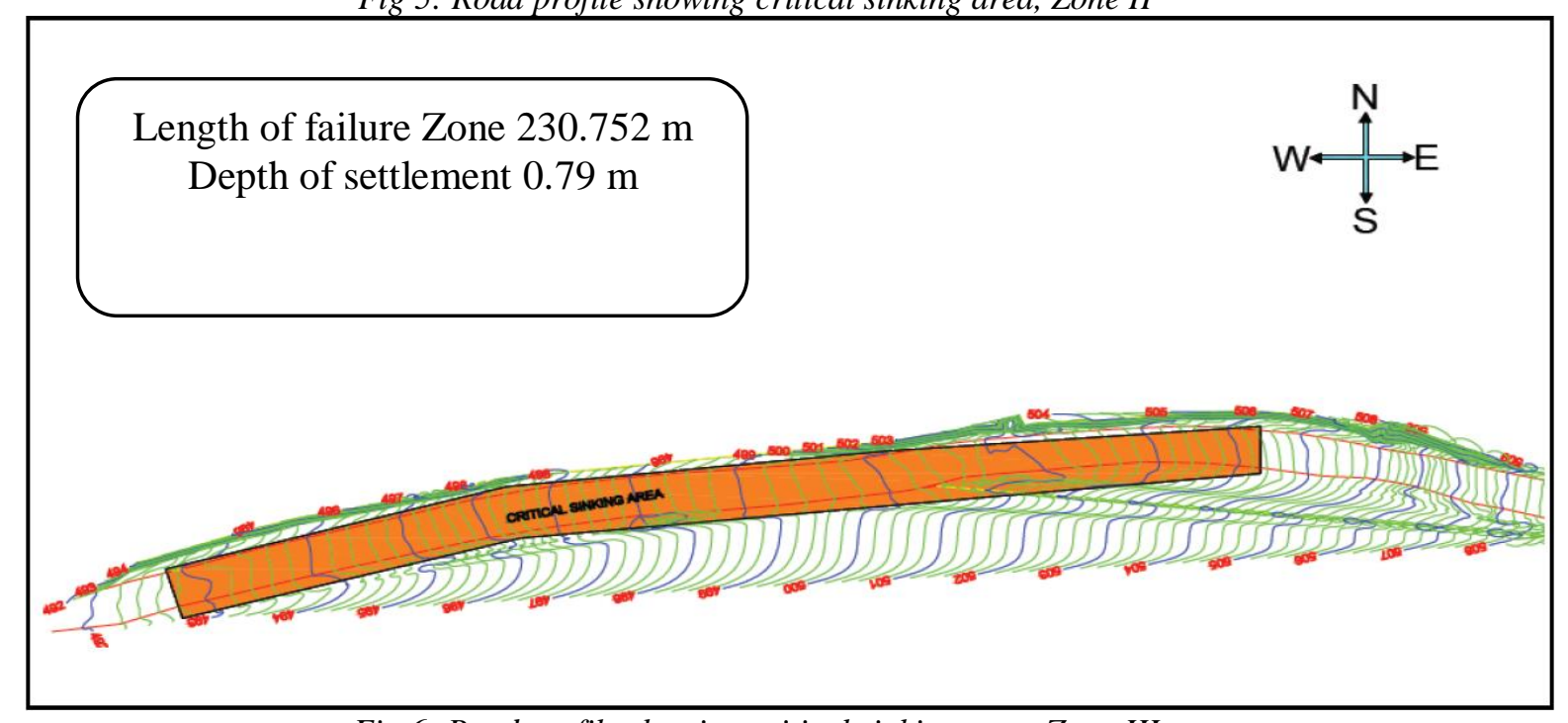

Fig 6: Road profile showing critical sinking area, Zone III

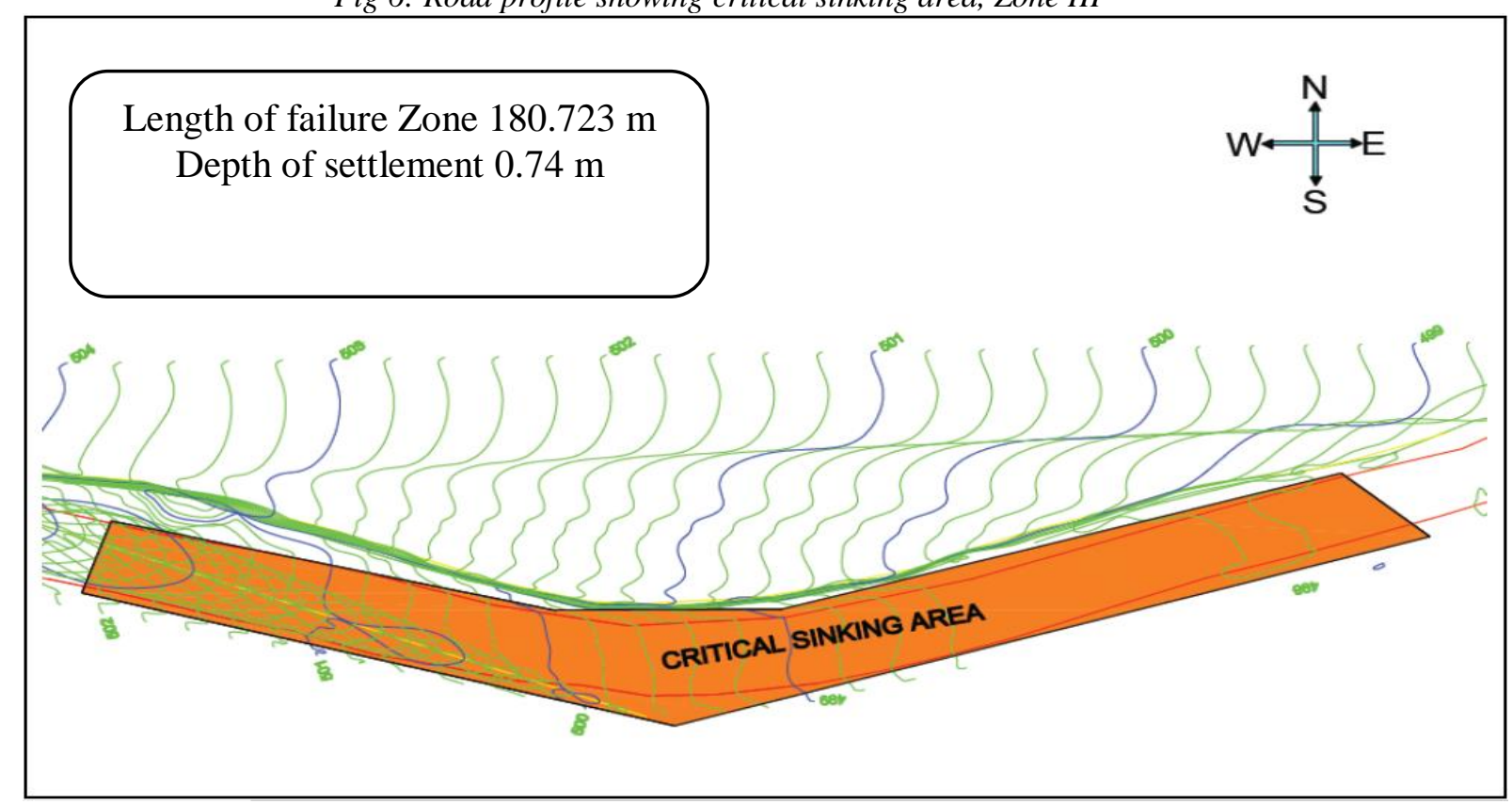

Fig 7: Road profile showing critical sinking area, Zone IV

2.2 Geotechnical Site Characterization 
The site investigation of the study area was achieved through trial pitting method. Three trial pits of dimension $1 \mathrm{~m} \mathrm{X} 1 \mathrm{~m} \mathrm{X} 1.5 \mathrm{~m}$ were dug at the three zones in the study area. Due to difficult terrain features of the ground, digging of pit at zone III was not feasible. Site investigation from the trial pits under this project were obtained by two methods:

- By Physical observation / visual investigation of the soil strata in the field.

- By conducting laboratory tests.

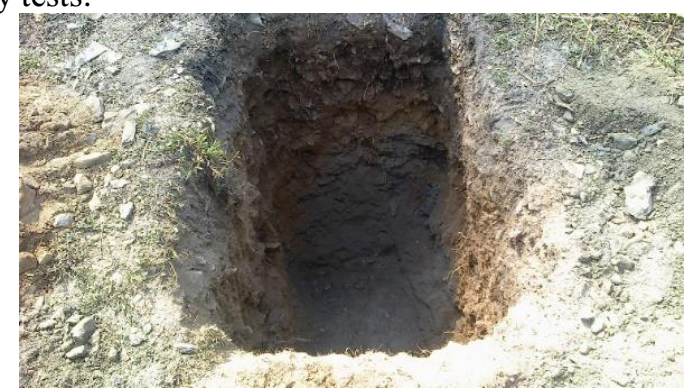

Fig 8: Trial pit sampling of study area

\begin{tabular}{|c|l|l|}
\hline SOIL PROFILE BASED ON PHYSICAL OBSERVATION IN THE \\
FIELD(Zone I)
\end{tabular}

Fig 9: Soil profile based on physical observation for zone I 


\begin{tabular}{|c|c|c|c|c|}
\hline \multicolumn{5}{|c|}{ SOIL PROFILE BASED ON LABORATORY TEST RESULT } \\
(Zone-I)
\end{tabular}

Fig 10: Soil profile based on laboratory test result for zone I

Soil profile is a natural succession of zones or strata below the ground surface and represents the alteration in the original soil material, which has been brought about by the weathering processes("Forecasting Landslide in Chhukha from index properties of soil-Research to policy Making," 2019). It may extent different depths at different places and each stratum may have varying thickness. Soil profile for zone 1 is illustrated here for both physical observation (figure 9) and laboratory analysis (figure 10)

\subsection{Subsurface Soil Exploration}

The Electrical resistivity test for sub surface profiling of the soil strata at the demarcated zones were conducted. Electrical resistivity test is found to be quick and reliable tool to classify and predict physical properties of materials based on the ease at which electric current can pass. The test requires inserting four test rods into the test area, in a straight line, equally spaced and all at a depth of $229 \mathrm{~mm}(9 \mathrm{in}$.). A constant current is injected into the earth from the earth resistance tester through the two outer test rods. The voltage drop resulting from the current flow through the earth is then measured across the inner two test rods. Most testers are designed to provide a direct reading in ohms. This value is then used in one of the following formulas to calculate the soil resistivity $(\rho)$ of the tested area. $\rho=2 \pi \pi \times A \times R$

Where: $\rho=$ soil resistivity in $\Omega-m$

$\mathrm{A}=$ Distance between test rods $(\mathrm{m})$

$\mathrm{R}=$ Resistance obtained from tester (in ohms)

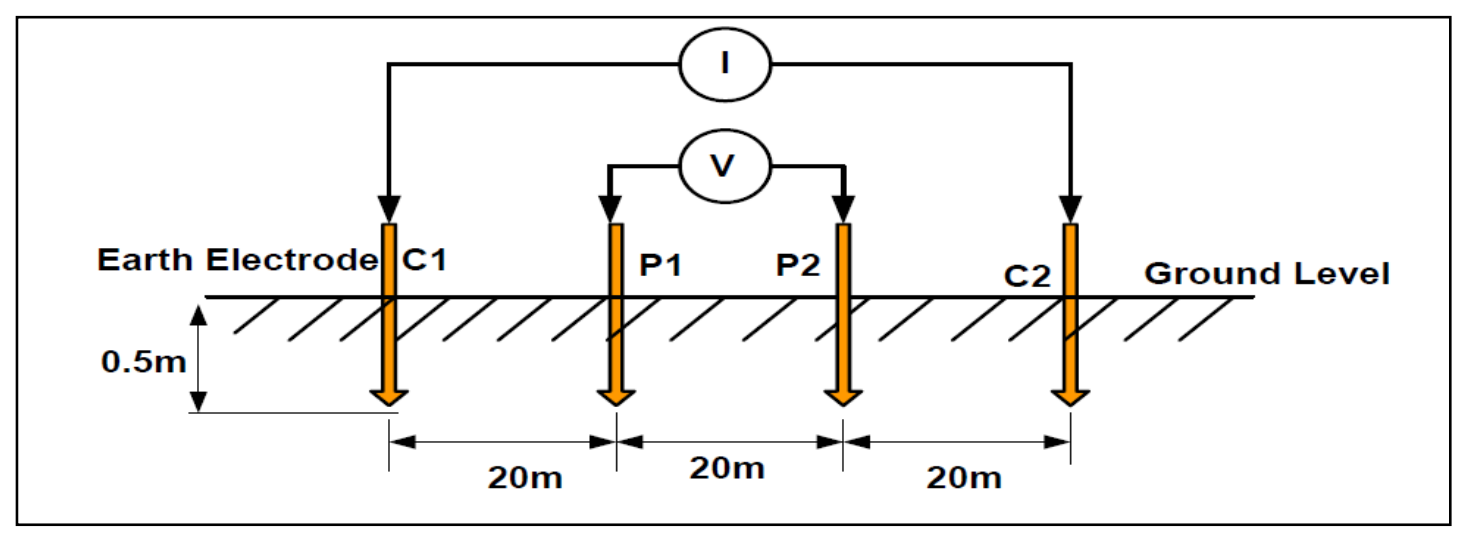

Fig 11: Wenner's four pin method 


\section{RESULTS AND DISCUSSIONS}

The topographic survey outcomes indicated settlement of $0.54 \mathrm{~m}, 0.81 \mathrm{~m}, 0.79 \mathrm{~m}$ and $0.74 \mathrm{~m}$ for Zone I, II, III and IV respectively caused due to sinking effect as represented in table 1 . The shallow soil profiling and classification were carried out on Zone I, Zone II and Zone III. The predominant soil type in all the zones were identified as coarse-grained soil with little fine content.

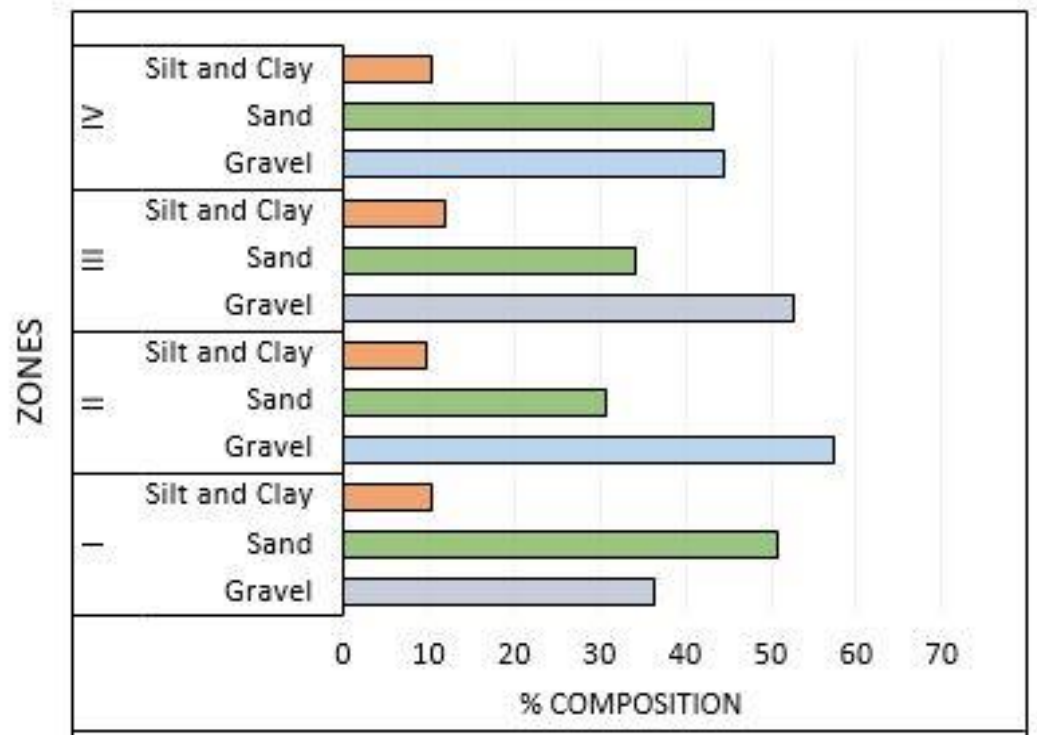

Fig 12: Soil classification

The deeper sub-surface exploration was also conducted. Sub-surface exploration using Wenners 4 Spike Method, a resistivity test, was conducted in all the zones. The resistivity value obtained in each layer were evaluated to correlate to the sub-surface soil characteristics. The soil profile indicated high content of gravel, coarse sand and silt of high permeability value which contributed to sinking of the pavement in all the critical zones.

The permeability value ranged from $5.5 \times 10-4 \mathrm{~cm} / \mathrm{s}$ to $5.05 \times 10-1 \mathrm{~cm} / \mathrm{s}$. Based on the soil profile and the high permeability value, the alternative solution of pile foundation with rigid pavement are proposed. This solution is realized as permanent solution as it derives load bearing capacity from skin frictional resistance and the end bearing resistance from the rigid stratum approximately $18.0 \mathrm{~m}$ from the ground surface.

\section{CONCLUSION}

The field investigation for the assessment of road subsidence along the Phuentsholing- Thimphu highway at Sorchen and Kamji have shown four critical pavement sinking zones. These zones were identified and briefly elaborated to the best of its technical details above. The detail survey was carried out to forecast the better understand the road subsidence in the study area. The technical detail of subsidence of highway are interpreted in the paper. To assess the site characteristics of the critical sinking zones, the geotechnical site investigation was carried out through physical observation at the site, laboratory test and field exploration in each zone. Based on those tests, the shallow soil profiling and classification were carried out. The predominant type of soil identified in all the zones are coarse grained soil with little fine content. Sub-surface exploration using Wenners 4 Spike Method, a resistivity test, was conducted in all the zones. The resistivity value obtained in each layer were evaluated to correlate to the sub-surface soil characteristics. The soil profile indicated high content of gravel, coarse sand and silt of high permeability value which contributed to sinking of the pavement in all the critical zones. The permeability value ranged from $5.5 \times 10-4 \mathrm{~cm} / \mathrm{s}$ to $5.05 \times 10-1 \mathrm{~cm} / \mathrm{s}$. Based on the soil profile and the high permeability value, the alternative solution of pile foundation with rigid pavement are proposed. This solution is realized as permanent solution as it derives load bearing capacity from skin frictional resistance and the end bearing resistance from the rigid stratum approximately $18.0 \mathrm{~m}$ from the ground surface. 


\section{RECOMMENDATION}

This research provides the paramount parameters for the future explorer who are interested to carry out the research in the site. The organization such as Thromde and city corporation can visualize the extend of road failure for the development activities. Future researchers can also work on collecting the soil samples from the sites where no settlement has taken place for laboratory test and analysis and field test to be conducted for further exploration. It is recommended to adopt Refraction test for subsurface exploration over Electric Resistivity Test for better results. The cause of road settlement in this study has been explained as non-homogeneity of soil stratum for different layers and its permeability. Other factors such as ground water table, seismic activity, and rainfall may be considered for future researchers. The cause of landslide in Sorchen could be carried out through the same methodology adopted in this research considering more factors. Through the soil exploration tests carried out at Sorchen in this study, the principal cause of road settlement identified was the appreciable permeability of the soil strata determined in all the four zones. However, there could be other contributing factors causing the settlement which the future researchers can work on. Hence, the need for slope stability analysis in Sorchen is felt necessary.

\section{REFERENCES}

1. Arora, D. K. (2009). Soil Mechanics and Foundation Engineering (Geotechnical Engineering). Delhi: Standard Publisher Distribution.

2. Burt, R. (2009). Soil Survey Feld And Laboratory Methods Manual. Lincoln, Nebraska: US Department of Agriculture. Dafalla, M. A. (2012). International Journal Of Electro-Chemical Science. Influence of Physical Parameters and Soil Chemical Composition on Electrical Resistivity: A guide For Geotechnical Soil Profiles, 3191-3204.

3. Dr. Alam Singh, D. G. (2004). Geotechnical Testing And Instrumentation. New Delhi: CSB Publishers And Distribution.

4. Gabriel A. Adegboyega, K. O. (September 2011). Journal of Academic and Applied Studies Vol. 1(3). Assessment of Soil Resistivity on Grounding of Electrical System: A Case Study of North East Zone, Nigeria, 28-38.

5. Gopal Ranjan, R. A. (2000). Basic and Applied Soil Mechanics. New Delhi: New Age International(P). ltd.

6. Group, A. L. (December 2007). Land Subsidence and Earth Fissures in Arizona. Research and Information Needs for Effective Risk Management.

7. J.Edmonds, W. (1992). Soil Profile Description Manual. Blacksburg, Virginia: Virginia Tech.

8. Kinzang Wangchuk, C. D. (June 2012). International Journa Of Advanced Scientific Research and Technology Issue 2, vol. 3. Creation of Physical Characteristics Information for Landslides Disaster Management Along Phuentsholing-Thimphu Highway, Bhutan Using Remote Sensing And GIS, 398-411.

9. Mittal, S. (2000). Soil testing for engineers. New Delhi: Khanna publishers.

10. Punmia, D. B. (March 2005). Soil Mechanics and Foundations 16th Edition. New Delhi: Laxmi Publications (P) LTD.

11. Murthy, S. (2009). Soil Mechanic and Foundation Engineering. CBS Publisher and Distribution Pvt. Ltd.

12. Froehling, R. (May 2, 2002). Report of Sub Surface Exploration and Geotechnical Engineering Evaluation. Roanoke, Virginia: Engineering Society of Science, US.

13. N. Chettri, R. Sarkar, K. Adhikari, I. bdr (2019).Forecasting Landslide in Chhukha from index properties of soil-Research to policy Making. (2019).

14. K. Tempa, N. Chhetri, I Bdr, Y. D. (2016). 8 th International. 8th International Civil Engineering Congress, (December), 295-303. 